\title{
Designing Digital Payment Artifacts
}

\author{
Olsen, Mia; Hedman, Jonas; Vatrapu, Ravi
}

Document Version

Final published version

Published in:

ICEC'12

DOI:

$10.1145 / 2346536.2346568$

Publication date:

2012

License

CC BY-NC-ND

Citation for published version (APA):

Olsen, M., Hedman, J., \& Vatrapu, R. (2012). Designing Digital Payment Artifacts. In R. Srivastava, S. Miller, \& $\mathrm{L}$. Ee-Peng (Eds.), ICEC '12: Proceedings of the 14th Annual International Conference on Electronic Commerce (pp. 161-168). Association for Computing Machinery. https://doi.org/10.1145/2346536.2346568

Link to publication in CBS Research Portal

\section{General rights}

Copyright and moral rights for the publications made accessible in the public portal are retained by the authors and/or other copyright owners and it is a condition of accessing publications that users recognise and abide by the legal requirements associated with these rights.

Take down policy

If you believe that this document breaches copyright please contact us (research.lib@cbs.dk) providing details, and we will remove access to the work immediately and investigate your claim. 


\section{Designing Digital Payment Artifacts}

\author{
Mia Olsen \\ Department of IT Management, \\ Copenhagen Business School \\ Howitzvej 60 \\ 2000 Frederiksberg, Denmark \\ + 4538153815 \\ mo.itm@cbs.dk
}

\author{
Jonas Hedman \\ Department of IT Management, \\ Copenhagen Business School \\ Howitzvej 60 \\ 2000 Frederiksberg, Denmark \\ + 4524794310 \\ jh.itm@cbs.dk
}

\author{
Ravi Vatrapu \\ Department of IT Management, \\ Copenhagen Business School \\ Howitzvej 60 \\ 2000 Frederiksberg, Denmark \\ + 4524794315 \\ vatrapu@cbs.dk
}

\begin{abstract}
Ubiquitous and pervasive computing is fundamentally transforming product categories such as music, movies, and books and the associated practices of product searching, ordering, and buying. This paper contributes to theory and practice of digital payments by conducting a design science inquiry into the mobile phone wallet (m-wallet). Four different user groups, including young teenagers, young adults, mothers and businessmen, have been involved in the process of identifying, developing and evaluating functional and design properties of m-wallets. Interviews and formative usability evaluations provided data for the construction of a conceptual model in the form of sketches followed by a functional model in the form of low-fidelity mockups. During the design phases, knowledge was gained on what properties the users would like the m-wallet to embody. The identified properties have been clustered as 'Functional properties' and 'Design properties', which are theoretical contributions to the on-going research on m-wallets. One of the findings from our design science inquiry into $\mathrm{m}$-wallets is that everyday life contexts require that evaluation criteria have to be expanded beyond "functionality, completeness, consistency, accuracy, performance, reliability, usability, fit with the organization, and other relevant quality attributes" [12] that are used within current design science work.
\end{abstract}

\section{General Terms}

Design, Human Factors.

\section{Keywords}

M-wallet, e-wallet, mobile payments, digital payments, design science, cashless society.

\section{INTRODUCTION}

The digital revolution continues to transform most aspects of our daily life. In particular, the digital revolution has resulted in the vertical convergence of business channel capacities and the horizontal integration of marketing departments [16]. The digital revolution also continues to transform the public sector organizations and services [15] towards an envisioned cashless society [9]. Additionally it is now possible to make purchases on the go with mobile payments transacted through mobile phones

(c) 2012 Association for Computing Machinery. ACM acknowledges that this contribution was authored or co-authored by an employee, contractor or affiliate of the national government of Denmark. As such, the government of Denmark retains a nonexclusive, royalty-free right to publish or reproduce this article, or to allow others to do so, for Government purposes only.

ICEC '12, August 07 - 08 2012, Singapore, Singapore Copyright 2012 ACM 978-1-4503-1197-7/12/08 ..\$10.00
[2].

With this comes the need for a personal information system to manage such mobile transactions. Further, ubiquitous and pervasive computing is fundamentally transforming product categories such as music, movies, and books and the associated practices of product searching, ordering, and buying. Therefore, a potential next step in the digital revolution is the transformation of the time honored traditional physical wallet into the mobile phone wallet (m-wallet).

There are many mobile payment solutions, but most of them have failed or their adoption rate has been lower than expected [17]. One reason for this is that payment is an institutional act integral to every day life, which cannot be easily changed. Payment is transacted in almost the same way worldwide. Further issues arise when companies additionally develop their own electronic payment systems, such as those for public transportation and retail chains [4]. So, there is a need for standardization of mobile payments [13]. Additionally, it has been suggested that technological development of such solutions should be directed towards a closer cooperation with users [7], and that future mobile payment research should focus on usability, as this is an unexplored area of mobile payments $[17,21]$. Therefore, it was expected that some research had been done on how to involve consumers in the development of mobile payments, together with usability and interface design of an m-wallet. But searching for these topics in the library and Google Scholar resulted in case studies and papers on technical design [5, 23, 29], security [10, $18,19]$ adoption, and diffusion, and understanding user motivations $[6,17,27]$ Consequently, there is a need for working with usability and user involvement when designing mobile payments solutions for the future. Set within this context, the purpose of this paper is to identify the functional and design properties of $\mathrm{m}$-wallets, with functional referring to what functions the m-wallet should hold and design referring to how the user can interact with and navigate the m-wallet.

\section{M-WALLETS}

A wallet is typically " a flat, folding pocketbook, especially one large enough to hold paper money, credit cards, driver's license, etc., and sometimes having a compartment for coins." Building on the above, we offer the following definition of an m-wallet:

An $m$-wallet is a personalized digital artifact that contains electronic payments instruments such as virtual currencies and payment cards, repository for receipts and tickets, identification cards such as passports, drivers' licenses and insurance cards, and personal items such as pictures and shopping lists.

\footnotetext{
${ }^{1}$ http://dictionary.reference.com/browse/wallet
} 
However, both in the extant literature and in commercial solutions the m-wallet has been understood in the very limited and restricted sense of a digital payment tool, such as PayPal and MPESA. This study is the first step towards addressing the previous limitations in conceptualizing and implementing m-wallets. It seeks to investigate realistic use cases and usage scenarios, in order to provide a holistic design of $\mathrm{m}$-wallets.

The idea of paying with mobile phones is, however, not new. Since the beginning of the 2000's it has been possible to buy digital content such as ring tones and games through mobile phones, and pay for it through mobile telecom operator billing systems. This made mobile payment services a critical issue of concern, and they were commonly perceived as a "killer application" for mobile commerce. Many mobile and electronic payment solutions have been introduced ever since, but most of them have failed or have had a low penetration rate [17]. One exception is Sony, NTT DoCoMo, and local banks in Japan that formed a joint venture in 2004 and launched a mobile payment system. Another exception is M-PESA (' $M$ ' is for mobile and 'PESA' is the Swahili word for cash) in Kenya. Yet another successful new electronic payment system is PayPal. Initially PayPal enabled people to perform transactions of small payments by means of e-mails. Back in 2006 PayPal launched PayPal Mobile, but even though it was improved and adjusted a couple of times to be compatible with several smartphones, it never provided an ability to transact through the phones to buy goods or services wirelessly.

It is argued that electronic payments have several advantages such as accessibility, convenience, speed, privacy and control, and that electronic payments are preferred in simple routine service transactions. It is suggested that mobile payments should not imply advanced multi-step procedures; PIN codes are preferred for identification and authentication; and consumers consider mobile payment useful if it is able to constitute several plastic cards [6]. The reasons for using traditional human assistants are security concerns and the opportunity to get help when skills with new technologies are lacked or the system malfunctions. A mobile payment channel should therefore furthermore communicate a high level of security and contain a helpful design that guides the user by means of careful communication, in order to make the user feel as comfortable using the new payment channel, as when using the traditional payment channels [17]. With regard to design properties the results show that mobile payments should be deducted from an already existing account [17], that payments should be made through another technology other than text messages [17], and that transactions need to be recorded locally on the mobile phone for documentation matters as well as on the distributed databases. An additional design property identified in the literature is the display of current balance that can be seen before making a transaction [20]

Besides what can be found in the literature, a look at the cashless payment systems themselves gives us an idea of how they work. In a review of 10 payment applications (including VISA payWave, MasterCard PayPass, PayPal Mobile, Google Wallet, Paybox, Banxafe, Oyster Card, Octopus Card, M-PESA, and SMART Money) 65 different design properties were identified. In Table 1, a selection of the systems and the most frequent properties are shown.

Table 1. Emerging Payment Systems and their Properties

\begin{tabular}{|c|c|c|c|c|c|c|c|c|}
\hline \multirow[b]{2}{*}{ Properties } & \multicolumn{8}{|c|}{ Systems } \\
\hline & $\begin{array}{c}\text { VISA / } \\
\text { Master } \\
\text { Card }\end{array}$ & $\begin{array}{l}\text { PayPal } \\
\text { Mobile }\end{array}$ & $\begin{array}{l}\text { Google } \\
\text { Wallet }\end{array}$ & Banxafe & $\begin{array}{l}\text { Oyster } \\
\text { Card }\end{array}$ & $\begin{array}{l}\text { Octopus } \\
\text { Card }\end{array}$ & M-PESA & $\begin{array}{l}\text { SMART } \\
\text { Money }\end{array}$ \\
\hline SMS and app based system & & & & $\mathrm{X}$ & & & $\mathrm{x}$ & $\mathrm{X}$ \\
\hline App access to system & & $X$ & & $X$ & & & $X$ & $X$ \\
\hline NFC based & $X$ & & & & $X$ & $X$ & & \\
\hline Purchasing list & & $\mathrm{X}$ & $\mathrm{X}$ & & & & & $\mathrm{X}$ \\
\hline Multiple accounts & & $\mathrm{x}$ & $\mathrm{x}$ & & & & & $\mathrm{X}$ \\
\hline Balance in SMS & & & & $\mathrm{X}$ & & & $\mathrm{X}$ & $\mathrm{X}$ \\
\hline Balance on receipt & & & & & & $\mathrm{X}$ & $\mathrm{X}$ & $\mathrm{X}$ \\
\hline Recipient list & & $\mathrm{X}$ & & & & & $\mathrm{X}$ & $\mathrm{X}$ \\
\hline $\begin{array}{l}\text { Merchants must activate the } \\
\text { sale / initiate sales }\end{array}$ & $\mathrm{X}$ & & & $\mathrm{X}$ & & $\mathrm{X}$ & & \\
\hline $\begin{array}{l}\text { Many steps to complete the } \\
\text { transaction }\end{array}$ & & $\mathrm{X}$ & & $X$ & & & $\mathrm{X}$ & $\mathrm{X}$ \\
\hline Transfer of money to friends & & $\mathrm{X}$ & & & & & $\mathrm{X}$ & $\mathrm{X}$ \\
\hline On-line access to user account & & & & & $\mathrm{X}$ & $\mathrm{X}$ & & $\mathrm{X}$ \\
\hline Payment history & & $\mathrm{X}$ & $\mathrm{X}$ & & $\mathrm{X}$ & $\mathrm{X}$ & & $\mathrm{X}$ \\
\hline Bank account prerequisite & $X$ & $\mathrm{X}$ & $\mathrm{X}$ & $X$ & $\mathrm{X}$ & & & \\
\hline $\begin{array}{l}\text { Creation of virtual account } \\
\text { prerequisite }\end{array}$ & & $\mathrm{X}$ & & $\mathrm{X}$ & $\mathrm{X}$ & $\mathrm{X}$ & $\mathrm{X}$ & $\mathrm{X}$ \\
\hline PIN code for purchase & & $\mathrm{X}$ & $\mathrm{X}$ & $\mathrm{X}$ & & & $\mathrm{X}$ & $\mathrm{X}$ \\
\hline User account needed & & $\mathrm{X}$ & $\mathrm{X}$ & & $X$ & $\mathrm{X}$ & $\mathrm{X}$ & $\mathrm{X}$ \\
\hline
\end{tabular}




\section{METHOD}

The choice of method for this study was driven by the research problem, which is the identification of m-wallet properties with focus on the interaction between the user and the artifact. The focus on human-computer interaction leads to issues that are complex and grounded in multiple disciplines. Consequently, questions frequently arise that have a thin or no theoretical background, and exploring these, is where Design Science Research - exploring by building - proves useful [11,25].

\subsection{The design process}

There are several guidelines and approaches on how to conduct design science projects $[12,25,26]$. In this project we draw upon Takeda et al.'s [24] design science model. The model has clear stages with deliverables and it has been recently applied in recent information systems research [25]

The process starts with an Awareness of the Problem phase, which typically comes from wonder or a problem in current practice that the researcher aims to solve. The output of this phase is a description of the problem and a proposal for researching this problem. The following phase is Suggestions for a Problem Solution phase and drawn from existing knowledge (literature and existing artifacts), followed by an attempt to implement an artifact based on the suggested solution (called the Development phase). Knowledge in the Suggestions phase may refer both to solutions from other areas, theories, or idea from potential users. In the Development phase, an attempt to develop and implement an artifact according to the suggested solution is performed. It is in this Development phase that most of the design takes place. The techniques for implementation vary, depending on the artifact to be constructed. The implementation itself can be very ordinary and does not need to involve innovation beyond the state-ofpractice for the given artifact; the innovation is in the design, not the construction of the artifact. The output of this phase is findings about the artifact's application and functionality. Afterwards an Evaluation phase starts where the implementations is assessed, and finally, a Conclusion phase indicates that the design project is finished by deciding that the results are "good enough", and by summarizing what the contributions of the artifact are. The phases Development, Evaluation, and further Suggestions are iterative until the results reach saturation [24].

\subsection{User involvement and data collection}

The 42 users (study participants) involved in this project were mainly found at Facebook among peripheral acquaintances and friends of friends, in order to keep prior knowledge of the interviewees to a minimum and minimize biases. A further selection criterion for the study participants was the degree of use of technology in their everyday lives, as this was estimated to be necessary in order for them to be able to understand the m-wallet concept. The number of study participants was 26 for the Suggestion phase and 16 for the Evaluation phase (See Table 2 for a summary). They were all Danish and mixed from the Copenhagen area and the western part of Zealand. The participants representing the Young Teenagers were mainly female, the participants representing the Young Adults were a mix of male and female, the Mothers are obvious, and the participants representing Business People were all male. None of the study participants from the Suggestion phase participated in Evaluation phase.

The study participants for both phases represented four different user groups: Young Teenagers, Young Adults, Mothers and
Business People. The reason for choosing these four user groups is that they loosely cover the phases of Wells and Gubar's widely used consumer life cycle [28]. The interaction time between researcher and study participant varied from 15 to 60 minutes and were conducted in the autumn of 2010. To avoid the issue of the artificial environment intimidating the study participant, the interviews were held at a place chosen by them, mainly their residence or work place.

Table 2. Study participant demographics

\begin{tabular}{lccll}
\hline $\begin{array}{l}\text { User } \\
\text { groups }\end{array}$ & Participants & Age & $\begin{array}{l}\text { Time } \\
\text { Period }\end{array}$ & Location \\
\hline Suggestion phase & & & & \\
\hline $\begin{array}{l}\text { Young } \\
\text { Teenagers }\end{array}$ & 8 & $13-$ & Sep-Dec & Home\&School \\
Young & & 15 & & \\
Adults & 8 & $19-$ & Sep-Dec & Home\&Library \\
Mothers & 5 & $32-$ & Sep-Oct & Home\&Work \\
& & 37 & & \\
$\begin{array}{l}\text { Business } \\
\text { People }\end{array}$ & 5 & $46-$ & Sept- & Home\&Work \\
\hline Evaluation phase & & 53 & Dec & \\
\hline Young & 4 & 15 & Jan & Home \\
Teenagers & & & & \\
Young & 4 & $20-$ & Jan & Home \\
Adults & & 22 & & \\
Mothers & 4 & $30-$ & Jan & Home \\
& & 37 & & Home\&Work \\
Business & 4 & $46-$ & Jan & \\
People & & 53 & & \\
\hline & & & & \\
\hline & & & & \\
\hline
\end{tabular}

\section{RESULTS}

\subsection{The Awareness and Suggestion phase}

The starting point of the design process was the identified shortcoming of a real $\mathrm{m}$-wallet and knowledge about its design properties. This Awareness was grounded in the literature and in review of existing mobile payment solutions.

In the Suggestion phase the work with the proposal from the previous phase (Awareness) was initiated. The work with the Suggestion phase took its starting point in the users; 26 people were interviewed during this phase. We recruited study participants from the four user groups based on the assumption that the groups would differ from each other, regarding their needs and expectations to the wallet. Munck [20] emphasizes that the understanding of end-users' behaviors and needs is a success criterion for contactless and mobile payments. This phase involved three steps: Usability goals, sketching and scenarios.

\subsection{Development phase}

In the development phase, we created four m-wallet mock-ups based on the input from the 26 interviews in the Suggestion phase. The creation of the four mock-ups included usability goals, sketching, personas and scenarios. The usability goals were written based on what the interviewees had said during the interviews; the sketches were based on initial sketches of the mwallet drawn by the interviewees; the personas were created based on the interviews and corresponding to the four user groups; and 
the scenarios covered the four personas interacting with each their m-wallet sketch.

Usually, a mock-up is used as a topic for conversation in for example an interview, but the mock-ups in this study were used as prototypes. A prototype is a more or less functional model that enables stakeholders to interact with the imagined product. Figure 1 shows the prototype that was developed for the Business Person. In that way, the prototype can be tested by the intended users in realistic environments, which leads to the designers' becoming aware of design issues they had not thought of themselves. A prototype is of great help in the design process because of the fact that the designers are brought to perceive completely new considerations, when they are going to take something from inside their minds and turn it into something physical and/or digital.

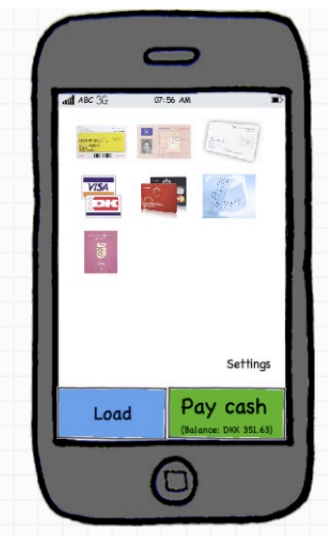

Figure 1. The Business Person's first m-wallet prototype.

\subsection{Evaluation phase}

After having developed the mock-ups, they were used as prototypes for the Evaluation phase, which consists of reflection through interaction and discussion with users to understand to what extent the artifact fills in the imperfections made explicit in the proposal from the Awareness of Problem phase. As Hevner et al. [12] explain it: "A design artifact is complete and effective when it satisfies the requirements and constraints of the problem it was meant to solve."

The Evaluation phase focuses on what went good or badly, and decides whether or not an iteration more is needed. During this phase we involved 16 people; four study participants from each of the four user groups evaluated their own user group's prototype during two rounds of user tests. The questions asked were concerned with:

- The study participants' understanding of the m-wallet's properties

- What impression they got when they first saw the m-wallet

- What they thought about the properties that was specific for the m-wallet compared to the physical wallet

- If they would like to have any other properties in the wallet

- Three things that they liked and three things that they disliked from the m-wallet

In the interaction with the study participants a revision of the prototypes was conducted, which formed input to the conclusion phase.

\subsection{Conclusion phase}

Based on the user tests in the Evaluation phase, some overall findings were made, e.g. the study participants for the second mock-up of the Young Teenager's m-wallet, reflected upon how many items in the m-wallet, they would like to secure with PIN code or a password, in order to prevent strangers spending their money or using personal data, if the mobile phone should get lost or stolen. The study participants furthermore considered it insecure to have the passport in the m-wallet, but disagreed on how many of the m-wallet's cards should be secured. One of the usability goals that were identified in the Development phase was safety, and this has thus not been fully reached, as the m-wallet that was tested not made the participants feel completely safe.

The study participants additionally proposed new properties for the m-wallet, e.g. a text appearing when payment is completed, a 'Cancel' and a 'Load' button on the payment page, bus passes, a possibility to change the structure of the $\mathrm{m}$-wallets front page, a bank application, and many more. All these additional properties indicate that more functionality is needed in the m-wallet, and therefore one of the other usability goals set up in the Development phase, the goal of utility, has not been reached.

During the user tests regarding the second mock-up of the Mother's m-wallet, one of the study participants proposed a text appearing on the m-wallet's screen when payment is completed. The adding of an eBanking function, a receipt option, and an automatic scanning of membership cards were proposed as well. A further suggestion was that the payment methods should include the user's different accounts, as a user might have more than one bank account. Moreover, the participants had different suggestions for what should happen to the receipts if an m-wallet was introduced, and a further investigation of this matter is therefore needed. All these things lead to the conclusion that the usability goal of utility is far from being reached by this version of the m-wallet. Through the user tests of the second mock-up representing the Business Person's m-wallet it became clear that a category structure was preferred to the structure with all cards visible on the wallet's front page. The m-wallet would therefore reach one of the other usability goals, the goal of learnability, to a greater extent, if the category structure were applied. An additional thing that would improve the learnability is the moving of the receipts from their present place, into the 'Payment methods' where the test users thought they belonged.

\subsection{Functional and design properties}

Besides what can be concluded on an overall level from the user tests of the four mock-ups, specific user requirements were also derived from the sketches drawn by the interviewees and from what the study participants said during the user tests of the mockups. In Table 3 these user requirements are clustered into functional and design properties across the four user groups. The functional properties are clearly representing the role of a wallet in everyday life and it varies greatly among the user groups. The Business Person has the greatest demand regarding the functionality of the m-wallet - it has to support all the business people's requirements. For instance, it was required that the $\mathrm{m}$ wallet should be able to hold many different cards for both credit and loyalty program. The passport and other travel documents were also clear requirements. In addition, business people put more emphasis on convenience and ease of use and less on security. The Young Teenagers, Young Adults, and Mothers had similar requirements. 
Table 3. Functional and Design Properties of m-wallets

\begin{tabular}{|c|c|c|c|c|}
\hline \multirow[b]{2}{*}{ Functional Properties } & \multicolumn{4}{|c|}{ User Groups } \\
\hline & Young Teenager & Young Adult & Mother & $\begin{array}{l}\text { Business } \\
\text { Person }\end{array}$ \\
\hline Health card & $\mathrm{X}$ & $\mathrm{X}$ & $\mathrm{X}$ & $\mathrm{X}$ \\
\hline Driver's license & & $\mathrm{X}$ & $\mathrm{X}$ & $\mathrm{X}$ \\
\hline Payment card(s) & $\mathrm{X}$ & $\mathrm{X}$ & & $\mathrm{X}$ \\
\hline 'Membership cards' category & & & & $\mathrm{X}$ \\
\hline Receipts & $\mathrm{X}$ & $\mathrm{X}$ & & $\mathrm{X}$ \\
\hline Gift vouchers & $\mathrm{X}$ & & & \\
\hline Hotel / car rental cards & & & & $\mathrm{X}$ \\
\hline 'ID cards' category & & & & $\mathrm{X}$ \\
\hline Currency converter & & & & $\mathrm{X}$ \\
\hline Amounts given in two currencies when abroad & & & & $\mathrm{X}$ \\
\hline Total amount of goods being bought & $\mathrm{X}$ & $\mathrm{X}$ & $\mathrm{X}$ & $\mathrm{X}$ \\
\hline Headline on front page saying 'Your electronic wallet & & & & $\mathrm{X}$ \\
\hline Headline on payment page stating the payment method & & & & $\mathrm{X}$ \\
\hline Service message (illustrated as yellow circle with a number) & & & & $\mathrm{X}$ \\
\hline 'Pay' button & $\mathrm{X}$ & $\mathrm{X}$ & $\mathrm{X}$ & $\mathrm{X}$ \\
\hline 'Load' / 'Transfer' button & & $\mathrm{X}$ & $\mathrm{X}$ & $\mathrm{X}$ \\
\hline Shortcuts to most used functions & & & & $\mathrm{X}$ \\
\hline eBanking shortcut & $\mathrm{X}$ & & & \\
\hline 'Back' button on the payment page & & & & $\mathrm{X}$ \\
\hline An icon structure & $\mathrm{X}$ & $\mathrm{X}$ & $\mathrm{X}$ & $\mathrm{X}$ \\
\hline Icons placed from the top of the wallet and downwards & $\mathrm{X}$ & $\mathrm{X}$ & & $\mathrm{X}$ \\
\hline Icons placed in the bottom of the wallet & & & $\mathrm{X}$ & \\
\hline Balance a part of the 'Pay' button on the front page & $\mathrm{X}$ & $\mathrm{X}$ & & \\
\hline Balance placed near the 'Pay' button on the front page & & & $\mathrm{X}$ & \\
\hline Balance placed above the list of what is being bought on the payment page & & & & $\mathrm{X}$ \\
\hline 'Pay' button in the bottom of the wallet's front page & $\mathrm{X}$ & $\mathrm{X}$ & & \\
\hline 'Pay' button in the middle of the wallet & & & $\mathrm{X}$ & \\
\hline 'Pay' button on the payment page & $\mathrm{X}$ & $\mathrm{X}$ & & $\mathrm{X}$ \\
\hline Payment card icon in the bottom of the wallet next to 'Pay' button & $\mathrm{X}$ & & & \\
\hline 'Load' button in the bottom of the wallet next to 'Pay' button & & $\mathrm{X}$ & & \\
\hline 'Load' button on the payment page & & & & $\mathrm{X}$ \\
\hline 'Transfer' button above the icons & & & $\mathrm{X}$ & \\
\hline Total amount of goods being bought visible on the payment page & $\mathrm{X}$ & $\mathrm{X}$ & & $\mathrm{X}$ \\
\hline
\end{tabular}


The design properties represent how the users would like to interact with the m-wallet. Here the requirements were more diverse than for functional properties across the user groups. The only common requirement is the icon structure. Otherwise it is clear that personal preferences and experience have influence on the design. Only five functional and design properties are universally required across the four user groups, including health card, passport, balance, total amount, and icon structure. Interestingly, the Business Person user group identified 27 functional and design properties and was thus the user group requiring the largest variety of properties. In summary, this tells us that functionality might be more important for the professional user segment, while aesthetic and experiential aspects of design should be prioritized for the young teenager and young adult user groups. For the Mother user group and other user groups with time pressures, a minimalistic m-wallet is to be designed.

\section{DISCUSSION AND CONCLUSION}

In the final section we discuss the findings of the $\mathrm{m}$-wallet design project in relation to the design of m-wallets and its practical relevance. We then conclude the paper.

\subsection{Design of $\mathrm{m}$-wallets}

A finding that emerged from our project is that the functional and design properties of $\mathrm{m}$-wallets are somewhat different to those of mobile payment (when comparing Table 1 to Table 3 ). Another finding is that the way the user tests of the mock-ups were conducted proved to be useful for this project, as this approach provided explanations when needed. Some of study participants had difficulties grasping the idea of an m-wallet. On the other hand, those who understood the concept of m-wallet right away had many questions, especially concerning security and other aspects of mobile payments that are still uncertain. Security issues are one aspect that needs to be further explored and not only in the case of m-wallet but also for mobile shopping. Further, designing for security issues might be in conflict with other usability goals such as efficiency and learnability. The user tests also revealed that it is of great importance when testing an innovative product to ask the study participants to ignore the questions of whether they would use it, as this showed to affect a couple of the tests. Another observation showing that some participants did not quite grasp the idea was made when some of them suggested that the mwallet should hold the possibility of reading text messages and checking Facebook, as they would not want to be without it. Along the way, it was therefore decided to explain to the study participants that they still had all the other functions on the mobile phone, and that the m-wallet was just another function or just like another mobile app. Moreover, the user tests did inform further questions that had not been originally planned and which might not have been asked to all the participants. For example, if a participant proposed an idea that had not been proposed before, the participants in the subsequent tests were asked about this proposal, in order to have their opinion. This project was, however, an explorative design project, and nothing was given in advance. It was therefore a conscious research design decision to test several ideas. The design expert, in our context, is the person who has tested several kinds of solutions, in order to find the right one, and to learn from those who went badly.

\subsection{Practical relevance}

A big challenge in the work with the m-wallet was to clarify what functionalities it should ideally embody. There were almost as many opinions as there were study participants. Several new ideas were proposed through the last iteration of user tests and other user groups' designs of the m-wallet kept inspiring the study participants. The evaluation results showed that the usability goals had not been reached, and that another design iteration is needed. It is therefore concluded that the $\mathrm{m}$ wallet proposed by this project, is not yet ready to be launched. That said, it was neither the purpose nor the scope of this project to design a fully functional m-wallet. Instead, the objective was to document design and functional properties that can help inform further research into mobile payments in general and $\mathrm{m}$ wallets in particular. This has been achieved by proposing the set of design and functional properties for the m-wallet based on user centered design methods and by comparing these empirically derived design properties with those found in the extant literature and existing mobile payment solutions.

The design and functional properties for $\mathrm{m}$-wallets identified as being important to the four user groups in this study, is offered as theoretical contributions to the on-going research on $\mathrm{m}$ wallets.

\subsection{Concluding Words and Future Work}

It is argued that IS researchers should 'engage deeply and seriously with the artifacts' [22], and this is the kind of engagement that this paper presents, with the artifact being the m-wallet.

As a point of departure, this paper presented guidelines for the design of an m-wallet, found in the literature and existing solutions, and used these when developing prototypes of $\mathrm{m}$ wallets and when comparing these $\mathrm{m}$-wallets to existing mobile payment solutions. Thus the research for this paper contributes to a cumulative tradition as defined by Keen [14].

The user tests of these m-wallet prototypes that followed were carried out in settings far from where the m-wallet is supposed to be used. This has inevitably impacted the test results. Therefore, we propose that future user tests, should be carried out in the actual contexts in which the m-wallet is supposed to be used, in order to avoid treating the IT artifact as a 'black box' $[1,3]$. 'Black boxing' belongs in the connection view of IS, which is an early perspective of how IT related to the world. Today this perspective has changed to a fusion view of IS, which means that IT artifacts are no longer separable from users and the contexts in which they are used [8], and therefore IT artifacts have to be tested by real users, in real-world settings.

In future work, we furthermore propose to create and test one single $\mathrm{m}$-wallet for all users, by having participants from one user group to test another user group's mock-up. This would explore how the prototype would work for them and what changes they would propose. By switching mock-ups through several iterations of tests, the possibility of having one standard design with customization options satisfying all the users could thus be tested. However, this project did not take this approach and instead focused on developing different wallets for different user groups.

Finally, it was from the beginning assumed that a standardized m-wallet would hold many customization options and thereby be confusing to the user. This could lead to a situation where the 
user would not want to use the m-wallet. However, the evaluation revealed that all the user groups had actually suggested a settings function to be added to the wallet to allow for customization and personalization. However, it needs to be empirically explored if it is desirable for the users to have a multitude of options and the ensuing user interactions and user experience in real-world contexts as well as simulated living lab settings. We suggest that such an empirical project should be informed by a holistic concept of an m-wallet that is closer to the physical wallet both as a socio-cultural artifact as well as a socio-technical practice of payment.

\section{ACKNOWLEDGMENTS}

This work was carried with the generous support of Copenhagen Finance IT Region (www.cfir.dk) and was funded by the Danish Enterprise and Construction Authority grant number ERDFH09-0026.

\section{REFERENCES}

[1] Agarwal, R. and Lucas Jr. H.C. 2005. The information systems identity crisis: Focusing on high-visibility and high-impact research. MIS Quarterly. 29, 381-398.

[2] Bakkegaard, J. 2009. Danmarks nationalbank, working papers. 63.

[3] Benbasat, I. and Zmud R.W. 2003. The identity crisis within the is discipline: Defining and communicating the discipline's core properties MIS Quarterly. 27, 183-194.

[4] Bourreau, M. and Verdier M. 2010. Cooperation for innovation in payment systems: The case of mobile payments. Communications \& Strategies. 1, 79, 95-114.

[5] Chen, J.J. and Adams C. 2004. Short-range wireless technologies with mobile payments systems. Proceedings of the Sixth International Conference on Electronic Commerce (ICEC), Delft, The Netherlands, October 25-27, ACM International Conference Proceeding Series. 60.

[6] Dahlberg, T. and Mallat N. 2002. Mobile payment service development-managerial implications of consumer value perceptions. Citeseer.

[7] Dahlberg, T., Mallat N., Ondrus J. and Zmijewska A. 2008. Past, present and future of mobile payments research: A literature review. Electronic Commerce Research and Applications. 7, 2, 165-181.

[8] El Sawy, O.A. 2003. The is core ix: The 3 faces of is identity: Connection, immersion and fusion. The Communications of the Association for Information Systems. 12, 39, 588-598.

[9] Garcia-Swartz, D., Hahn R. and Layne-Farrar A. 2006. The move toward a cashless society: A closer look at payment instrument economics. Review of Network Economics. 5, 2, 175-197.

[10] Herzberg, A. 2003. Payments and banking with mobile personal devices. Communications of the ACM. 46, 5, 5358.

[11] Hevner, A. and Chatterjee S. 2010. Design science research in information systems. Design Research in Information Systems. 9-22.

[12] Hevner, A.R., March S.T., Park J. and Ram S. 2004. Design science in information systems research. Mis Quarterly. 28, 1, 75-105.

[13] Hilavuo, S. 2005. Business evolution of mobile services. Managing mobile services-technologies and business practices, Chichester. 17-45.
[14] Keen, P.G.W. Mis research: Reference disciplines and a cumulative tradition. Proceedings of the First International Conference on Information Systems, (Philadelphia, PA, December 8-10 1980). 9-18.

[15] Knights, D., Noble F., Vurdubakis T. and Willmott H. 2007. Electronic cash and the virtual marketplace: Reflections on a revolution postponed. Organization. 14, 6, 747.

[16] Li, H. and Leckenby J.D. 2007. Examining the effectiveness of internet advertising formats. Internet advertising: theory and research. 203.

[17] Mallat, N. 2007. Exploring consumer adoption of mobile payments: A qualitative study. The Journal of Strategic Information Systems. 16, 4, 413-432.

[18] Me, G. 2003. Payment security in mobile environment. Proceedings of the ACS/IEEE International Conference on Computer Systems and Applications, Tunis, Tunisia, July 14-18.

[19] Misra, S.a.W., N. . 2004. Security of a mobile transaction: A trust model. Electronic Commerce Research. 4, 4, 359372.

[20] M(29[unck, M.G. The future is contactless. Presentation from a get fit meeting at nets on the 30th of november 2010. 2010 [cited 2010 6th of December]; Available from: http://www.cfir.dk/Forside/Arrangementer/GetFITNovemberthe30th/Slidesfraarrangementet.aspx

[21] Ondrus, J. and Pigneur Y. 2006. Towards a holistic analysis of mobile payments: A multiple perspectives approach. Electronic Commerce Research and Applications. 5, 3, 246-257.

[22] Orlikowski, W.J. and Iacono C.S. 2001. Research commentary: Desperately seeking the "it" in it research - a call to theorizing the it artifact. Information Systems Research. 12, 2, 121-134.

[23] Pradhan, S., Lawrence E. and Zmijewska A. 2005. Bluetooth as an enabling technology in mobile transactions. Proceedings of the IEEE International Conference on Information Technology: Coding and Computing (ITCC), Las Vegas, NV, USA, April 4-6.

[24] Takeda, H., Veerkamp P. and Yoshikawa H. 1990. Modeling design process. AI magazine. 11, 4, 37.

[25] Vaishnavi, V. and Kuechler W. 2008. Design science research methods and patterns: Innovating information and communication technology, Boca Raton: Auerbach Publications xvi, $226 \mathrm{p}$.

[26] Van Aken, J.E. 2005. Management research as a design science: Articulating the research products of mode 2 knowledge production in management. British Journal of Management. 16, 1, 19-36.

[27] Van der Heijden, H. 2002. Factors affecting the successful introduction of mobile payment systems. Proceedings of the 15th Bled eCommerce Conference, Bled, Slovenia, June $17-19$.

[28] Wells, W.D. and Gubar G. 1966. Life cycle concept in marketing research. Journal of Marketing Research. 3, 4, 355-363.

[29] Zmijewska, A. 2005. Evaluating wireless technologies in mobile payments - a customer centric approach. Proceedings of the Fourth International Conference on Mobile Business (ICMB), Sydney, Australia, July 11-13. 